\title{
Fabrication and Microstructure Examination of Al-Sic Mmcs Via Stir Casting Technique
}

\author{
Sathiyaraj .S, B. Selvababu, Maqsood Ahmed, Baskar Balaji, Harsha Vardhan
}

\begin{abstract}
The function of engineering materials in the development of contemporary technology like steel Matrix Composites (MMCs) have evoked a keen hobby these days for capacity packages in aerospace and automobile industries as a result of their superior power to weight ratio and excessive temperature resistance. Aluminium (6061) and silicon Carbide (Powder) has been selected as matrix and reinforcement cloth respectively. On this gift look at an attempt is made to broaden Aluminium primarily based silicon carbide particulate MMCs. Stir casting is one of the maximum cost powerful technique of processing MMC and to gain homogenous dispersion of ceramic material. Al-SiC composites containing special weight chance three. Five \%, 7.Zero\% and $10.5 \%$ of $B 4 C$ have been fabricated via way of stir casting technique. Experiments are conducted with the aid of numerous weight fraction of SiC (3.5\%, 7.Zero\% and 10.Five\%), on the equal time as preserving all different parameters normal. The distribution of reinforcement and percent of composition are examined thru Optical Emission Spectrometer (OES). The compositions in their micro structural features were determined via Metallurgical Microscope.
\end{abstract}

Keywords : Silicon Carbide, Stir casting, Aluminium and metal Matrix Composite.

\section{INTRODUCTION}

A composite fabric is a fabric inclusive of or more bodily and/or chemically awesome levels. The composite generally has superior traits than the ones of each of the person components[1]. Commonly the reinforcing aspect is sent inside the non-stop or matrix element. Whilst the matrix is a metallic, the composite is called a Metal-matrix composite (MMC)[2]. In MMCs, the reinforcement typically takes the form of particles, whiskers, quick fibers, or non-stop fibers

Nowadays, the need for advanced engineering materials technologies for various software packages is growing[3]. For composites, materials are mixed in such a way that we can make greater use of their figure fabric while mitigating the effects of their deficiencies to some degree[4].

Revised Manuscript Received on December 16, 2019

* Correspondence Author

Sathiyaraj.S *, Mechanical Department, Aarupadai Veedu Institute O Technology, Vinayaka Mission's Research Foundation, Deemed To Be University, Chennai, India. Email: sathiyaraj@avit.ac.in

B.Selvababu, Mechanical Department, Aarupadai Veedu Institute Of Technology, Vinayaka Mission's Research Foundation, Deemed To Be University, TamilNadu, India.Email: selvababu@avit.ac.in

Maqsood Ahmed, Baskar Balaji, Harsha vardhan, Mechanical Department, Aarupadai Veedu Institute Of Technology, Vinayaka Mission's Research Foundation, Deemed To Be University, Tamil Nadu, India.

\section{OBJECTIVES OF THE PROJECT}

The targets of the challenge are:

The primary goal of this paper is to manufacture Al-SiC metallic Matrix composite with varying composition (3.Five \%, 7.Zero\% and 10\%) of reinforcement particles of Boron Carbide with the aid of the usage of stir casting technique.

The second one goal is the distribution of reinforcement and percent of composition are tested by Optical Emission Spectrometer (OES).The compositions in their micro structural functions had been decided by means of Metallurgical Microscope.

\section{CHOICE OF MATRIX}

\section{A. Aluminium 6061}

A commercial grade of $\mathrm{Al} 6061$ with a theoretical density of $2.7 \mathrm{~g} / \mathrm{cm} 3$ was used as a metal matrix material for aerospace, transport and marine applications as it has excellent mechanical properties like welding efficiency, welding strength, high corrosion resistance.Aluminium 6061 matrix as shown in figure 1 . The constitu 7 ents of $\mathrm{Al}$ 6061 have been given in Table I.

Table- I: Chemical composition of Al (6061)

\begin{tabular}{|c|r|r|r|r|r|r|r|r|}
\hline $\mathbf{S i}$ & $\mathbf{F e}$ & $\mathbf{C u}$ & $\mathbf{M n}$ & $\mathbf{M g}$ & $\mathbf{C r}$ & $\mathbf{Z n}$ & $\mathbf{T i}$ & $\mathbf{A l}$ \\
\hline 0.4 & & & & & & & & \\
& & & & & & & & \\
- & $0-$ & 0.15 & & $0.8-$ & $0.04-$ & & & \\
& & & $0.0-$ & & & $0.0-$ & $0.0-$ & Bal \\
0.8 & 0.7 & -0.4 & 0.15 & 1.2 & 0.35 & & & \\
\hline
\end{tabular}

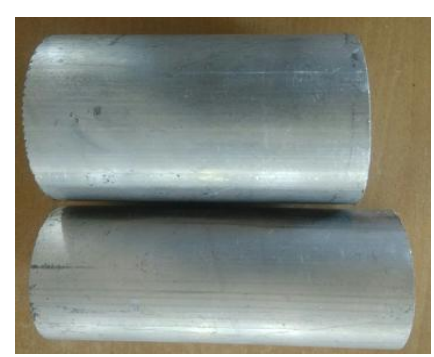

Fig. 1. Aluminium 6061 Matrix

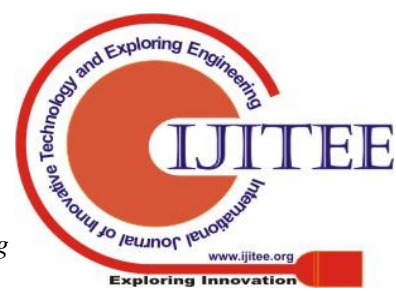




\section{B. Silicon Carbide}

Silicon carbide is used as reinforcement particle. It's miles a compound of silicon and carbon with chemical method $\mathrm{SiC}$. Its miles applied in abrasives, refractories, ceramics, and several high-general performance applications. Silicon carbide consists of tetrahedral of carbon and silicon atom with strong bonds inside the crystal lattice. This produces a completely hard and robust material. It has traits like low density, immoderate energy and thermal conductivity, low thermal enlargement and excessive hardness. The chemical composition and residences of the Silicon Carbide is given under Table II and Table 3.4.Silicon carbide powder as shown in Figure 2.The properties of Silicon carbide is illustrated in Table III.

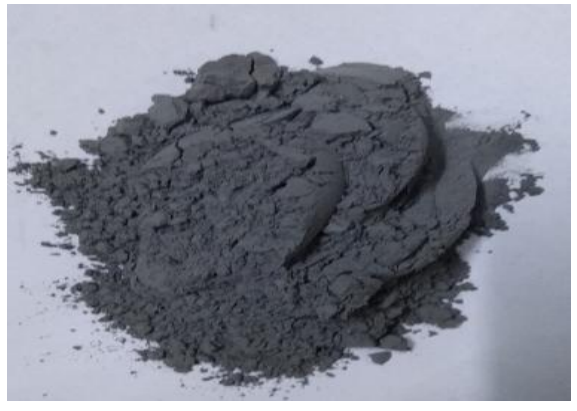

Fig. 2.Silicon Carbide Powder.

Table- II: Chemical Composition of Silicon Carbide

\begin{tabular}{|l|r|r|r|r|r|r|}
\hline Elements & Sic & $\mathrm{Sio}_{2}$ & $\mathrm{Si}$ & $\mathrm{Fe}$ & $\mathrm{Al}$ & $\mathrm{C}$ \\
\hline Percentage & Balance & 5 & 0.3 & 0.08 & 0.1 & 0.3 \\
\hline
\end{tabular}

Table- III: Properties of Silicon Carbide

\begin{tabular}{|c|l|l|}
\hline Sr. No. & Melting Point & $2200-2700^{\circ} \mathrm{C}$ \\
\hline 1 & Hardness $\left(\mathrm{Kg} / \mathrm{mm}^{2}\right)$ & 2800 \\
\hline 2 & Density $\left(\mathrm{g} / \mathrm{cm}^{3}\right)$ & 3.1 \\
\hline 3 & Coefficient of thermal expansion & $4.0\left(\mu \mathrm{m} / \mathrm{m}^{\circ} \mathrm{C}\right)$ \\
\hline 4 & Fracture toughness & $4.6 \mathrm{MPa}$ \\
\hline 5 & Poisson's Ratio & 0.14 \\
\hline 6 & Colour & Black \\
\hline
\end{tabular}

\section{MATERIALS AND METHODS}

Stir casting a number of the variety of manufacturing methods to be had for Metallic matrix composites (MMCs), stir casting system is traditionally standard as a primarily promising path nowadays commercially practiced. Its benefit is its simplicity, flexibility and applicability to a production in large amounts. First of all stirring device has been advanced by coupling motor with gearbox and a moderate steel stirrer. All the melting have become completed in a graphite crucible in an oil-fired furnace. Bars of aluminium 6061 have been preheated at a thousand for 3 to four hours earlier than melting and mixing the Silicon Carbide particles were preheated at $500^{\circ}$ For 1 to a few hours to make their surfaces oxidized.

The furnace temperature became first raised above the liquid us to soften the alloy scraps honestly and became then cooled down truely beneath the liquid us to preserve the slurry in a semi-strong country. At this stage the preheated Silicon Carbide debris had been introduced and combined through stir casting setup. After enough manual mixing become completed, The composite slurry has been reheated to a fully liquid country after which computerized mechanical mixing was shaped into a standard stirring price of $700 \mathrm{rpm}$ for approx 10 minutes. Inside

the final blending gadget, the furnace temperature modified into managed inside $760^{\circ} \mathrm{C}$. Pouring of the composite slurry has been done inside the die mould prepared in line with the size $(100 \mathrm{~mm} \times 100 \mathrm{~mm} \times 14 \mathrm{~mm})$. The important experimental setup used right here is stir casting and squeeze casting set up.Stir casting method is a especially low rate liquid processing gift to supply MMC and for this reason, this processing technique were utilized on this look at. Parent 4.1and four.2 suggests Stir casting setup used on this take a look at. Besides being easy, flexible, and attractive, as compared with other strategies; it also allows very large length components to be fabricated and is likewise relevant to big quantity manufacturing. Stir casting course additionally ensures that undamaged reinforcement materials are attained. Also fabricates Al-SiC MMCs specimen as shown in figure four.3. The varying compositions of samples are proven in table IV. Figure 3,4 and 5 shows the stir casting apparatus ,stir casting process, Al-SiC MMCs Specimen.

Table- IV: Composite of samplesSample of weight $=1250$

\begin{tabular}{|c|c|c|c|}
\hline $\begin{array}{c}\text { Sample } \\
\text { No }\end{array}$ & $\begin{array}{c}\text { Aluminium } \\
\text { (Grams) }\end{array}$ & $\begin{array}{c}\text { Silicon } \\
\text { Carbide(Grams) }\end{array}$ & Remarks \\
\hline 1 & 1206.25 & 43.75 & Al-3.5\%SiC \\
\hline 2 & 1162.50 & 87.50 & Al-7.0\%SiC \\
\hline 3 & 1118.75 & 131.25 & Al-10.5\%SiC \\
\hline
\end{tabular}

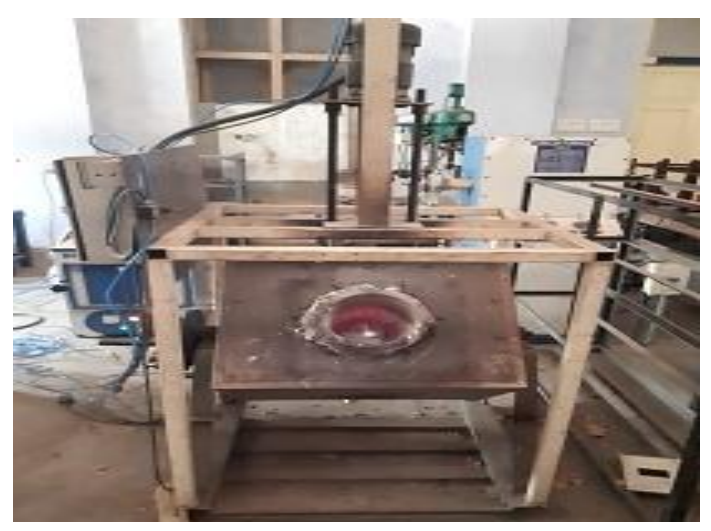

Fig. 3.Stir Casting Apparatus. 


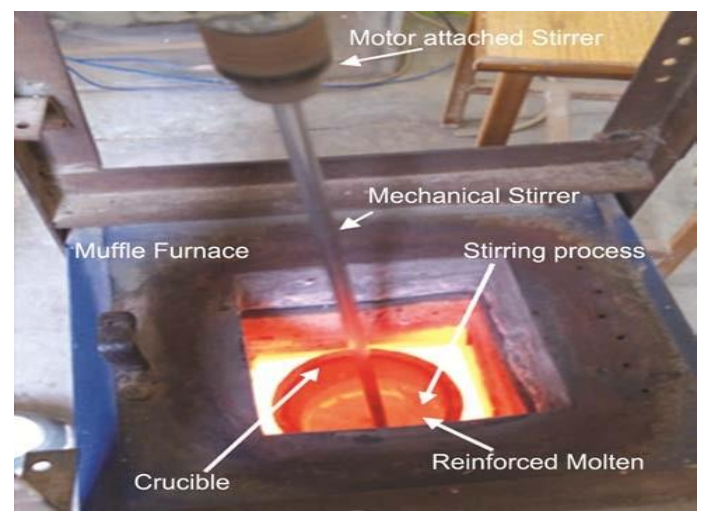

Fig. 4.Stir Casting Process .

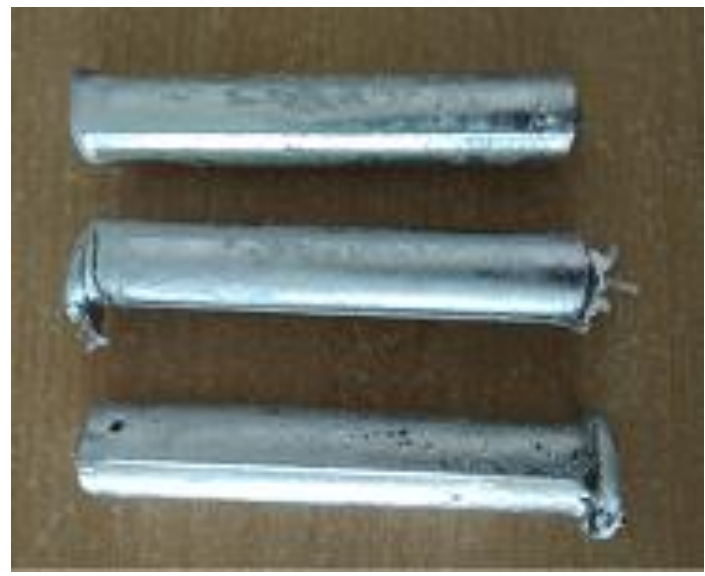

Fig. 5. Al-SiC MMCs Specimen.

\section{RESULT AND DISCUSSION}

Aluminium strengthened with Slicon Carbide particulate composites are efficiently fabricated by means of stir casting technique. The Metallurgical microscope views of the fabricated Al-SiC MMCs are demonstrated in figure 7,8 and 9. It is far determined from the rationality that for all wt hundred of reinforcement, Silicon Carbide particles are dispersed uniformly inside the aluminum matrix. Metallurgical Microscope Dewinter Tech device as validated parent figure 6 .

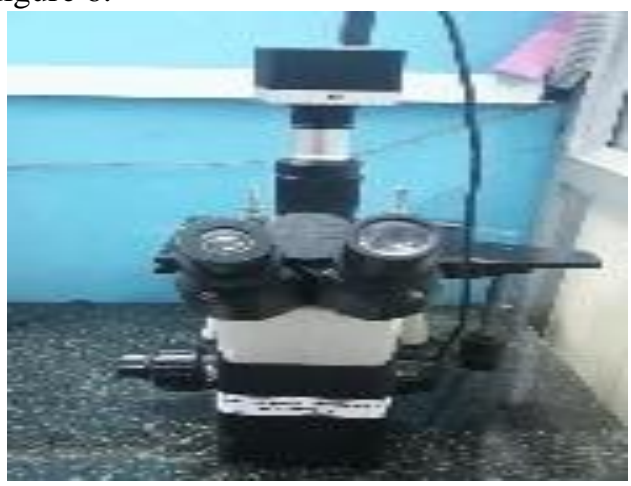

Fig. 6.Metallurgical Microscope Dewinter Tech Equipment.

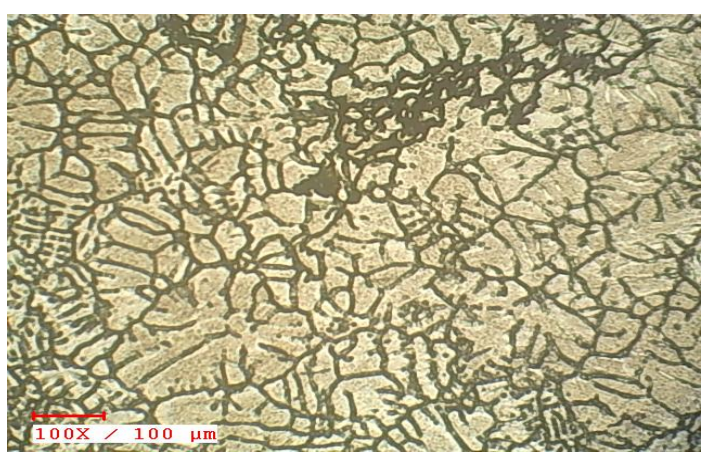

Fig. 7.Microstructure of Al-3.5\% SiC MMCs.

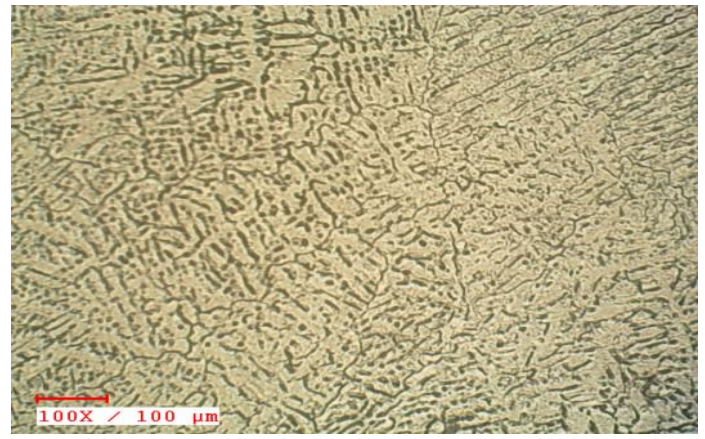

Fig. 8.Microstructure of Al-7.0\% SiC MMCs.

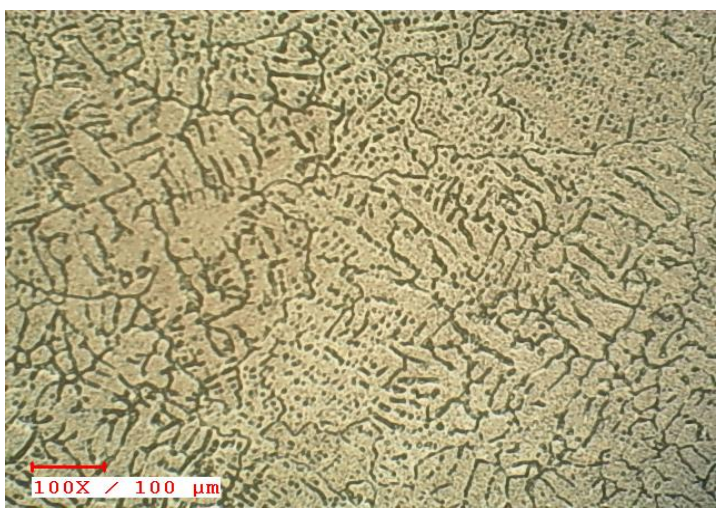

Fig. 9.Microstructure of Al-10.5\% SiC MMCs.

Chemical composition of the composite of $3.5 \% \mathrm{wt}, 7.0 \% \mathrm{wt}$ and10.5\%wt $\mathrm{Al}-\mathrm{SiC}$ was found to be as follows Table V.

Table- V: Composite of samples

\begin{tabular}{|l|c|c|c|}
\hline Composition & $\mathrm{Al}-3.5 \% \mathrm{SiC}$ & $\mathrm{Al}-7.0 \% \mathrm{SiC}$ & $\mathrm{Al}-10.5 \% \mathrm{SiC}$ \\
\hline Silicon & 0.669 & 0.744 & 0.864 \\
\hline Iron & 0.276 & 0.558 & 0.391 \\
\hline Copper & 0.261 & 0.166 & 0.188 \\
\hline Manganse & 0.046 & 0.101 & 0.117 \\
\hline Mangesium & 0.658 & 0.447 & 0.611 \\
\hline Chromium & 0.222 & 0.160 & 0.127 \\
\hline Zinc & 0.007 & 0.006 & 0.036 \\
\hline Titanium & 0.017 & 0.015 & 0.009 \\
\hline Aluminium & Balance & Balance & Balance \\
\hline
\end{tabular}

Published By:

Blue Eyes Intelligence Engineering

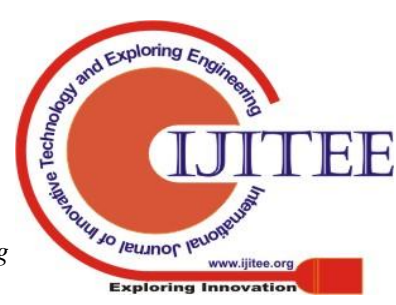




\section{CONCLUSION}

MMCs were produced through stir casting route with extraordinary wt\%(viz.,3.5,7.0\& $10.5 \mathrm{wt} \%$ ) of reinforcement and the microstructure, mechanical properties are evaluated. From the study the following conclusions are derived.

Production of Al-Silicon Carbide composites changed into finished efficiently.

The microstructure of Al-SiC MMCs was discovered to be Silicon Carbide particles are dispersed uniformly within the aluminium matrix for all wt $\%$ of reinforcement.

\section{REFERENCES}

1. Dasgupta ,H. Meenai," SiC particulate dispersed composites of an $\mathrm{Al}-\mathrm{Zn}-\mathrm{Mg}-\mathrm{Cu}$ alloy: Property comparison with parent alloy”, Materials characterization, Vol.54,No.4-5, May.2005,pp.438-45.

2. J. Jeykrishnan,B. V. Ramnath,X. H. Savariraj,R. D. Prakash,V. D. Rajan, D. D. Kumar," Investigation on tensile and impact behavior of aluminum base silicon carbide metal matrix composites", Indian journal of science and technology,Vol.37,No.9, oct.2016.

3. B. Ravi ," Fabrication and mechanical properties of Al7075-SiC-TiC hybrid metal matrix composites", International Journal of Engineering Science Invention, Vol.6,2017,pp.12-9.

4. J. Senthil Kumar," FABRICATION OF HTC PLANT FOR CARBONISATION OF MUNICIPAL SOLID WASTE",International Journal of MC Square Scientific Research, Vol.9, No.1 April 2017,pp.26-33.

\section{AUTHORS PROFILE}

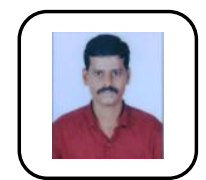

Sathiyaraj.S,Assistant Professor Mechanical Department, AarupadaiVeedu Institute of Technology, Vinayaka Mission's Research Foundation, Deemed To Be University. Having 8 years of experience. Life member in ISTE and ENFUSE.

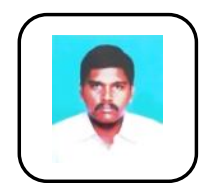

B.Selva Babu,Asst. Professor, Department of Mechanical Engineering, Aarupadai Veedu Institute of Technology, Vinayaka Mission Research Foundation, Deemed To Be University. Having 6 years of experience. Life member in ISTE.

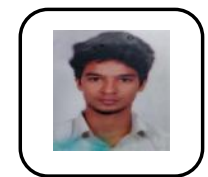

Maqood Ahmed ,UG Student Mechanical Department, AarupadaiVeedu Institute Of Technology, Vinayaka Mission's Research Foundation, Deemed To Be University.

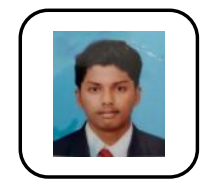

Baskar Balaji,UG StudentMechanical Department, AarupadaiVeedu Institute Of Technology, Vinayaka Mission's Research Foundation, Deemed To Be University.

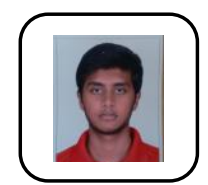

Harshavardhan, UG Student Mechanical Department, AarupadaiVeedu Institute Of Technology, Vinayaka Mission's Research Foundation, Deemed To Be University. 